\title{
Scaling resistance of special high performance composites with burnt clay additive
}

\author{
P. Reiterman, M. Jogl \& P. Konvalinka \\ Experimental Centre, Faculty of Civil Engineering, \\ Czech Technical University in Prague, Czech Republic
}

\begin{abstract}
This paper deals with the experimental study of the composition of special highperformance Portland cement based composites and their resistance to de-icing salt scaling. The aim of this was to evaluate the impact of pozzolanic additive burnt clay, the application of which is documented by several research works. Studied composites are formulated as fine-grain high performance concrete with high dose of Portland cement and silica fume and very low rate of water-cement ratio to ensure reduced permeability. Burnt clay was applied as cementitious supplementary material to reduce the environmental impact of concrete mixtures and to obtain suitable microstructure. Portland cement replacement by the above mentioned additive was gradually elevated just up to the rate of $60 \%$ of Portland cement weight. Investigation of scaling resistance was complemented by measuring surface water absorption and determination of flexural and compressive strength which exceeded the level of $100 \mathrm{MPa}$ for studied mixtures. Mechanical properties were not extensively affected by burnt clay additive, but the essential impact of studied pozzolanic material was noticeable in the case of scaling and absorption tests, which means processes regulated by permeability. In this point of view, optimum rate of replacement by burnt clay seems to be about $30 \%$ of Portland cement weight. A mixture with optimal composition exhibited increased durability by more than $50 \%$ to reference mixture. Application of burnt clay contributed to good potential for practical use for all tested properties with significant production energy savings.

Keywords: burnt clay additive, scaling resistance, freeze-thaw cycling, sorption.
\end{abstract}




\section{Introduction}

Modern solution in the building industry is the application of new generation of materials with increased utility properties. Development of these materials was caused by unsatisfactory parameters of traditional building materials especially in relation to resistance to environmental attack. Within the field of cement based composites the attention is given to development and design of new high performance composites. Extensive progress was allowed by the production of admixture and additives with significantly increased efficiency.

The term of HPC (high performance concrete) usually includes concretes with compressive strength higher than $60.0 \mathrm{MPa}$; in the case of UHPC (ultra HPC) where strength limit was established to $150.0 \mathrm{MPa}$ [1]. In the traditional concrete industry there are numerous solutions to produce concrete with higher mechanical and durability properties. Common ways are the optimization of aggregates granularity and low level of water-cement. Mentioned approaches cause low workability of fresh concrete. The use of HPC and UHPC is often presented as friendly to raw material utilization. General savings of raw materials are timed by longer lifetime of structures made of HPC and maintenance cost [2]. For some types of loading it is already unsuitable to use thin-walled elements, primarily in case of shear stress and dynamic loading [3]. That is why structures made of HPC and UHPC are presented especially by facing boards or bridge slab.

Besides the high mechanical properties mentioned, HPC has a good durability ensured by low water-cement and high amount of active additives. High dosage of active additives in NSC (normal strength concrete) causes a decrease of $\mathrm{pH}$ in hardened concrete and a loss of natural protection of steel reinforcement too, but with the use of pozzolanic additives following reaction providing substantial sealing effect of new hydrates, so carbonation is not accelerated by increased permeability. Unfortunately in the case of HPC low permeability means low resistance to fire [4] and extreme temperature loading where the material is damaged by escaping steam, other gases performing in concrete, or by formation of frost.

The scope of the present paper is to verify long-term resistance of HPC to the action of freeze-thaw cycling with parallel attack of de-icing salts. Examination of scaling resistance was complemented by measurement of mechanical properties and water sorption properties of studied HPC. The design of the mixture took into consideration the environmental aspect of developed mixtures because of the application of cement supplementary materials. Attention was paid particularly to burnt clay replacement whose pozzolanic properties was confirmed by number of research works [5-7]. Performed tests were provided at the age of 90 days due to the slower course of pozzolanic hydration processes. This topic is important with respect to the application of cement-concrete cover in roads and especially in highway construction. Low permeability and high amount of pozzolanic additives could prevent alkali-silicate reaction (ASR) of aggregates as well. Permeability is a principal property affecting the final ability of the material to resist attack from the environment - durability. 


\section{Experimental methods}

Determination of resistance of concrete surface to de-icing salts was investigated according to CSN EN 732326 - methodology C [8]. Testing consists of cycle temperature loading of cylinder samples with an average of $150 \mathrm{~mm}$, whose surface was covered by $3 \%$ solution of $\mathrm{NaCl}$. The load cycle starts with a frosting phase down to $-18^{\circ} \mathrm{C}$ lasting three hours and then continues by a defrosting period up to $5^{\circ} \mathrm{C}$ for another three hours. In the case of when the action of salts and frost gradually damages the loaded surface, the surface layer is lost into the salt solution in the form of surface waste. After each 25 cycles testing is interrupted and concrete waste is collected. The final amount of dried cumulative waste is expressed to unit area $\left(\mathrm{g} / \mathrm{m}^{2}\right)$. For transport structures the required waste is usually up to $1000 \mathrm{~g} / \mathrm{m}^{2}$ after 100 loading cycles. Introduced methodology is often marked as scaling resistance.

Compressive strength was investigated according to CSN EN 12390-2 [9] using cubic samples of $150 \mathrm{~mm}$ edge. Compressive strength is presented as critical strength after sample destruction. The final value of measurement is an average of at least three samples. Flexural strength was determined by using prismatic specimen of 100x100x400 mm. Measurement was organized as a three-point bending test with the support distance of $300 \mathrm{~mm}$ and axial loading [10].

Absorption was measured by using a cubic specimen with an edge of $100 \mathrm{~mm}$ which were partially wetted (just up to $5 \mathrm{~mm}$ ) into water basin. In selected time intervals was gravimetrically recorded growth of water mass absorbed into the hardened composite. Absorption coefficient $A\left(\mathrm{~g} / \mathrm{m}^{2} \mathrm{~s}^{1 / 2}\right)$ was calculated for 10 and 20 minutes for each mixture according (1), where $i$ is cumulative mass of water $\left(\mathrm{g} / \mathrm{m}^{2}\right)$ and $t$ time $(\mathrm{s})$. The above described test presents a very quick way of water capability assessment.

$$
i=A t^{1 / 2}
$$

\section{Studied materials}

Burnt clay is a pozzolanic material of high scientific interest in Czech Republic because of the available raw materials. The positive effect of metakaolin replacement of Portland cement in high strength concrete and high performance concrete has been verified in several research works $[7,11]$.

Burnt clay is produced by controlled silica-aluminous clay calcination when the temperature of calcination is dependent on the actual raw materials composition but generally it is just about $800^{\circ} \mathrm{C}$ [12]. The utilisation of calcined clay as a pozzolanic material for mortar and concrete has received considerable attention in recent years $[6,7,13]$. The chemical composition and specific surface area $\left(\mathrm{m}^{2} \cdot \mathrm{kg}^{-1}\right)$ measured by Blaine apparatus of used burnt clay MK is shown in Table 1. The composition of raw clay, predominantly kaolin content, used for calcination define final designation of the product. 
Table 1: Composition of used burnt clay.

\begin{tabular}{|c|c|c|c|c|c|c|c|c|}
\hline Component & $\mathrm{Al}_{2} \mathrm{O}_{3}$ & $\mathrm{CaO}$ & $\mathrm{SiO}_{2}$ & $\mathrm{Fe}_{2} \mathrm{O}_{3}$ & $\mathrm{Na}_{2} \mathrm{O}$ & $\mathrm{MgO}$ & $\mathrm{K}_{2} \mathrm{O}$ & $\mathrm{TiO}_{2}$ \\
\hline$(\%)$ & 47.30 & 0.20 & 49.10 & 0.90 & 0.05 & 0.10 & 0.50 & 1.60 \\
\hline
\end{tabular}

The chemical composition of all commonly used mineral additives is an essential material characteristic affecting properties of fresh and hardened concrete. Máca et al. [13] described the negative impact of metakaolin to workability of fresh concrete mixture. With further application of metakaolin of different quarry, and different chemical composition, very encouraging results were achieved which passed the requirements for self-compacting concrete.

High reactivity of burnt clay is strongly determined by its grading. Extremely fine ground burnt clays are not applicable for conventionally formulated Portland cement based mixture. Wider practical utilization can be found in the field of composites with polymer matrix or for gypsum modification to reach increased durability properties assessed by water transport limitation.

The detailed composition of developed mixtures is shown in Table 2. Each mixture consists of silica sand of different grading and a high amount of fine components. The binder system was modified by application of silica fume to reach suitable mechanical properties and to ensure high density of final hardened composites as well as suitable workability. Burnt clay was gradually dosed as cement supplementary material up to $60 \%$ of weight replacement. The water binder ratio was set as constant for all studied mixtures; silica flour was considered as inert additive.

Table 2: Composition of studied composites.

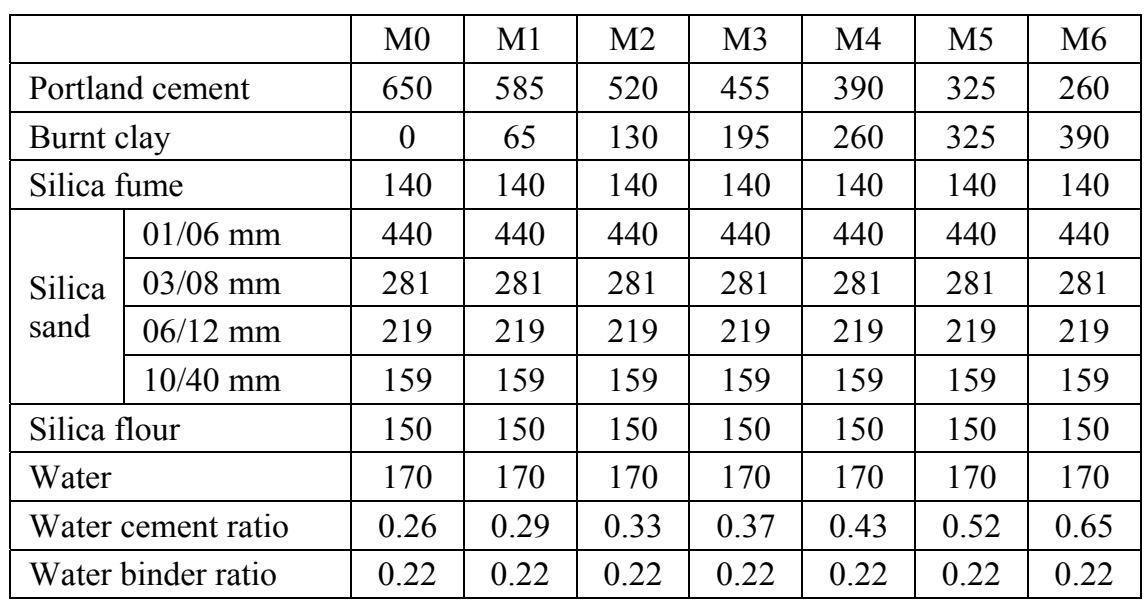




\section{Results and discussion}

The following text presents the results of measuring of compressive strength $\left(f_{c m}\right)$, flexural strength $\left(f_{t m}\right)$, bulk density, scaling resistance and sorption of all mixtures with different burnt clay replacement. All these values are presented at the age of 90 days. The values presented in Table 3 are the mean of three samples.

Table 3: Results of bulk density measuring and mechanical tests.

\begin{tabular}{|c|c|c|c|}
\hline & $\rho\left(\mathrm{kg} \cdot \mathrm{m}^{-3}\right)$ & $\mathrm{f}_{\mathrm{tm}}(\mathrm{MPa})$ & $\mathrm{f}_{\mathrm{cm}}(\mathrm{MPa})$ \\
\hline M0 & 2253 & 12.4 & 117.2 \\
\hline M1 & 2238 & 13.7 & 118.0 \\
\hline M2 & 2249 & 12.5 & 127.4 \\
\hline M3 & 2210 & 12.1 & 127.1 \\
\hline M4 & 2204 & 12.0 & 116.1 \\
\hline M5 & 2176 & 14.0 & 108.1 \\
\hline M6 & 2140 & 13.8 & 102.4 \\
\hline
\end{tabular}

Final values of bulk density are continuously reduced with increasing burnt clay replacement which is the expected result because of the higher bulk density of Portland cement used. Values of flexural strength are very similar which is very interesting; usually this is sensitive methodology to record changes in composites. Considerable differences are noticeable on the base of compressive strength determination. From this point of view, replacement of about $20 \%$ seems to be optimal. Figure 1 shows relative results of measured basic physical and mechanical properties. As a reference mixture (100\%) was considered mixture M0 - without burnt clay application.

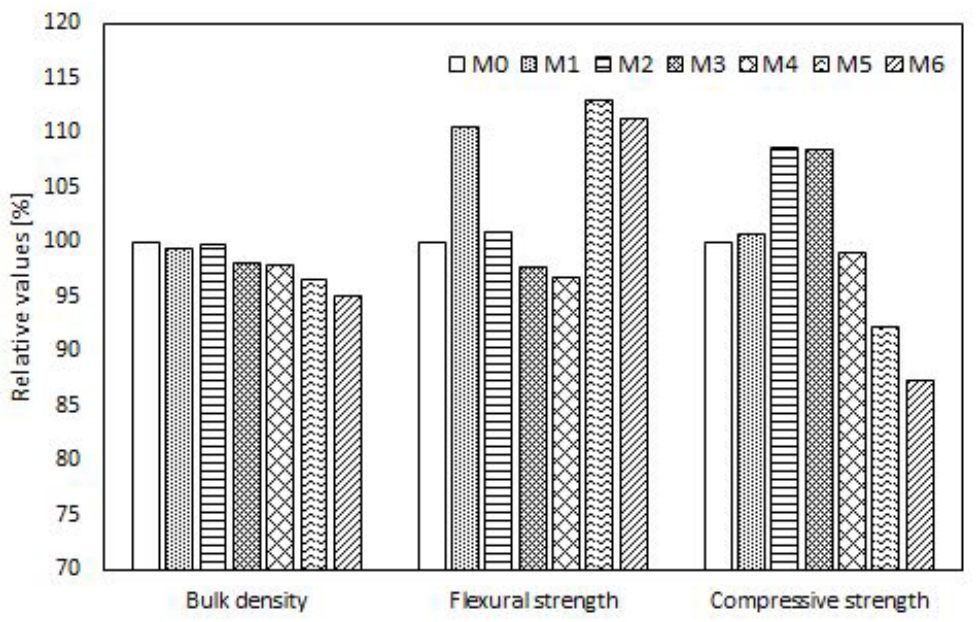

Figure 1: Relative values of measured properties. 
For commonly used concrete in the building industry, the maximum rate of $1000 \mathrm{~g} / \mathrm{m}^{2}$ after 100 freeze-thaw cycles is required, which was obtained in our results. Graphical illustration of performed test is shown in Figure 2. Scaling corresponds well with results of provided mechanical tests, especially compressive strength. This fact is quite interesting with regard to the mechanism of surface destruction where tensile stress concentrated along weak part of surface is deciding factor.

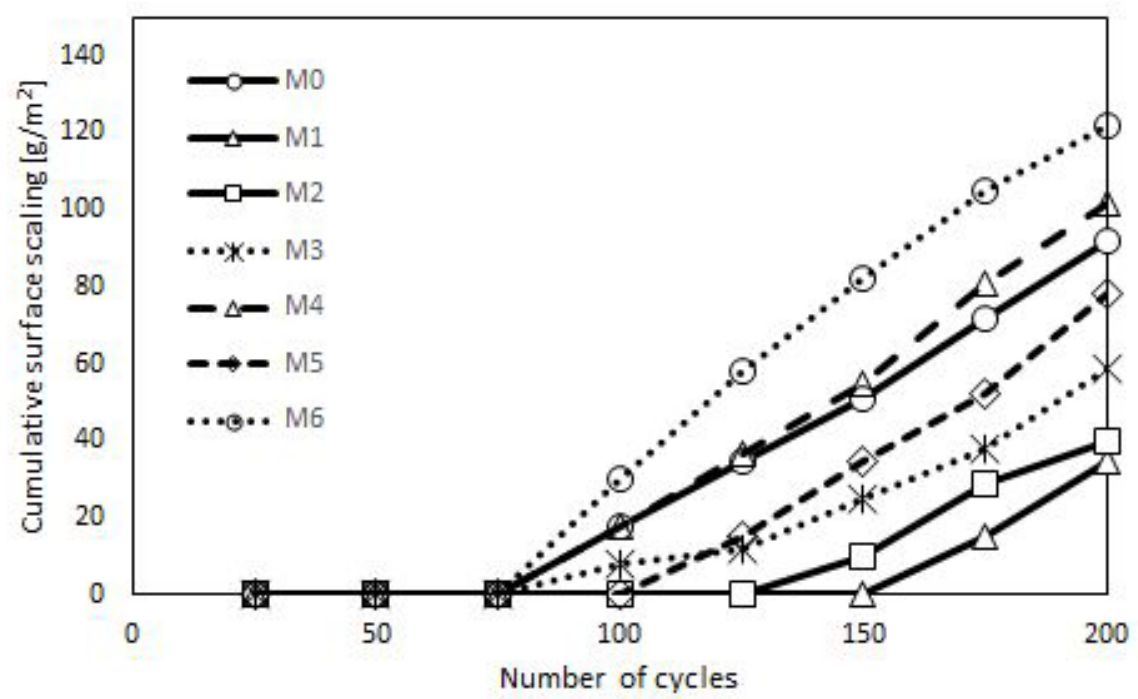

Figure 2: Evolution of surface scaling during freeze-thaw cycling.

Modification of the binder system by a burnt clay radically increased scaling resistance of all studied mixtures. This fact is interesting with respect to reduced mechanical properties of mixtures with replacement over $30 \%$. With the maximal dose of burnt clay was the final scaling resistance decreased in comparison to reference mixture.

Measuring of adsorption coefficient is often provided simultaneously with tests of frost of scaling resistance because of the influence of water content in capillary system.

Usually samples are tested after drying at $105^{\circ} \mathrm{C}$. But in the provided measurement, samples were kept in ambient laboratory conditions to simulate the real state of structure which is attacked by the environment. That is why values of adsorption coefficient are extremely low. Detailed results of the measurement are shown in Table 4 as well as values of adsorption coefficient for set time intervals. It is necessary to consider them as an indicative values. 
Table 4: Results of scaling resistance.

\begin{tabular}{|c|c|c|c|c|}
\hline \multirow{2}{*}{ Mixture } & \multicolumn{2}{|c|}{$\begin{array}{c}\text { Cumulative water mass } \\
\left(\mathrm{g} / \mathrm{m}^{2}\right)\end{array}$} & $\begin{array}{c}\text { Adsorption coefficient } \\
\left(\mathrm{g} / \mathrm{m}^{2} \mathrm{~s}^{1 / 2}\right)\end{array}$ \\
\cline { 2 - 5 } & 10 minutes & 20 minutes & 10 minutes & 20 minutes \\
\hline M0 & 150 & 150 & 0.000612 & 0.000433 \\
\hline M1 & 200 & 200 & 0.006325 & 0.004472 \\
\hline M2 & 150 & 150 & 0.001225 & 0.001225 \\
\hline M3 & 75 & 125 & 0.000530 & 0.000884 \\
\hline M4 & 125 & 125 & 0.001021 & 0.001021 \\
\hline M5 & 150 & 175 & 0.001732 & 0.001565 \\
\hline M6 & 250 & 300 & 0.002236 & 0.002683 \\
\hline
\end{tabular}

\section{Conclusions}

A set of trial mixtures of HPC with burnt clay replacement were tested in a performed experimental program. Previous research which focused on the study of different types of metakaolin on various properties of concrete confirmed a positive effect to final scaling resistance $[6,13]$, but such complicated binder system with another reactive additive has not yet been tested. Motivation for realized program was to reduce the environmental impact of energy consuming materials commonly used for HPC production. Efficiency of studied pozzolanic additive was evaluated on the basis of mechanical tests and durability tests simulating severe conditions of real structures. It was found that optimal dose of burnt clay of given chemical composition corresponds for all evaluating studied parameters.

Mechanical parameters, especially compressive strength, were positively affected by a dose of burnt clay of about 20-30\%. Final values of flexural strength did not reflect results of compressive strength determination which was caused by extreme low differences of relatively high level of flexural strength of all studied mixtures. Results of the scaling resistance test and the water adsorption test of orientation confirmed trend drawn by mechanical parameters.

All studied HPC mixtures with burnt clay replacement reach excellent results in comparison with reference mixture. Final scaling after 200 cycles of freezethaw loading together with de-icing salts attack was on the level of $60 \%$ of reference for the mixture with burnt clay addition with highest final scaling. Obtained results confirmed suitable properties for practical utilization.

\section{Acknowledgement}

This research has been supported by the Czech Science Foundation, under project number P105/12/G059. 


\section{References}

[1] Hájek, P., Fiala, C., Kynčlová, M.: Life cycle assessments of concrete structures - a step towards environmental savings. Structural Concrete, 12, pp. 13-22, 2011.

[2] Holčapek, O., Vogel, F., Vavřiník, T., Keppert, M.: Time Progress of Compressive Strength of High Performance Concrete. Experimental Stress Analysis 51 in Litomerice, pp. 167-172, 2014.

[3] Koteš, P., Farbák, M., Kotula, P., Brodňan, M., Čavojcová, A.: Using CFRP lamellas for strengthening of dynamically loaded beams. Procedia Engineering, 65, pp. 302-310, 2013.

[4] Bodnárová, L., Jarolím, T., Válek, J., Brožovský, J., Hela, R.: Selected properties of cementitious composites with Portland cements and blended Portland cements in extreme conditions. Applied Mechanics and Materials, 507, pp. 443-448, 2014.

[5] E. Vejmelková, D. Koňáková, M. Čáchová, R. Černý, M. Keppert. Effect of hydrophobization on the properties of lime-metakaolin plasters. Construction and Building Materials 37 (2012), pp. 556-561.

[6] Kolář, K., Reiterman, P., Klečka, T., Dudíková, M., Huňka, P.: Surface Layer Study of Concrete Containing Metakaolin. Concrete under Severe Conditions - Environment and Loading. Merida, pp. 675-692, 2010.

[7] Konvalinka, P., Litoš, J., Jandeková, D.: Volume changes of cement pastes using metakaolin. EAN 2012: Proceedings of the 50th Annual Conference on Experimental Stress Analysis, 2012.

[8] CSN EN 7323 26: Resistance of cement concrete surface to water and defrosting chemicals.

[9] CSN EN 12390-3: Testing hardened concrete - Part 3: Compressive strength of test specimens.

[10] Zatloukal, J., Jogl, M.: Test specimen for testing of cementitious composite fracture mechanics properties. EAN 2012: Proceedings of the 50th Annual Conference on Experimental Stress Analysis, 2012.

[11] Dinakar, P., Pradosh, K., Sriram, G., Effect of Metakaolin Content on the Properties of High strength Concrete. International Journal of Concrete Structures and Materials, 7, pp. 215-223, 2013.

[12] Vimmrová, A., Keppert, M., Michalko, O., Černý, R., Calcined gypsumlime-metakaolin binders: Design of optimal composition, 52, pp. 91-96, 2014.

[13] Máca, P., Konvalinka, P., Jandeková, D.: The influence of metakaolin addition on the scaling of concrete due to frost action. Cement Wapno beton, 19/1, 2014. 